\title{
An Investigation of Work-Related Stress among High School Teachers in the Hhohho Region of Swaziland
}

\author{
Ceasar S. Dlamini \\ University of Swaziland, Kwaluseni Campus \\ Email: cizadlamini@gmail.com \\ Chinedu I. 0. Okeke \\ University of Fort Hare, East London Campus, RSA \\ Email: cokeke@ufh.ac.za, \\ Kuttickattu J. Mammen \\ University of Fort Hare, East London Campus, RSA \\ Email:kmammen@ufh.ac.za
}

Doi:10.5901/mjss.2014.v5n15p575

\begin{abstract}
This study sought to investigate the work-related stress among high school teachers in the Hhohho region of Swaziland. It followed the descriptive-correlation research design and adopted the Person-Environment Fit theory. The target population of this study was all qualified teachers teaching in high schools in the Hhohho region of Swaziland. The sampling procedure that was employed to select the schools and the teachers to participate in this investigation was simple random sampling. A pilot testing was conducted. Validity and reliability of instruments were attended to. Required permissions were obtained from relevant authorities and the sample gave informed consent. Questionnaire response rate was $82 \%$. Quantitative data were analysed using the Statistical Package for the Social Sciences (SPSS) version 10.0. The findings of the study showed that high school teachers in the Hhohho region of Swaziland are moderately stressed. Relevant recommendations are given.
\end{abstract}

Keywords: Work stress, teacher stress, sources of teacher stress, Swaziland.

\section{Introduction}

Research into work-related stress has been an ongoing activity (see for example, Pettergrew \& Wolf, 1982; Kompier \& Cooper, 1999; Montgomery \& Rupp, 2005; Chan, Chen \& Chong, 2010; Sliskovic \& Sersic, 2011; ETUCE, 2011; Kaur, 2011; van Zyl \& van Zyl, 2012). Kompier \& Cooper (1999) compiled and consolidated the incidence, causes and prevention in different types of work places in several European countries. While van Zyl and van Zyl (2012) researched work-related stress among middle level managers from the service sector while other researchers were focusing on teachers' stress either in schools (Pettergrew \& Wolf, 1982; Montgomery \& Rupp, 2005; Kokkinos, 2007; Chan, Chen \& Chong, 2010; Sliskovic \& Sersic, 2011; ETUCE, 2011; Kaur, 2011) or in higher education (Loate \& Marais, 1996; Sliskovic \& Sersic, 2011). Although research on teachers' stress has been continuing, no such studies were conducted in Swaziland's Hhohho region and hence, this study was necessary.

\subsection{Stress, health and human well-being}

Stress refers to the combination of physiological and psychological reactions that negatively affect an individual as a result of environmental conditions. Antonious and Cooper (2005) define stress as a form of emotion, an automatized response to the perception of threat. Researchers have noted that people's psychological reactions to the world around them can create wear and tear on their bodies that may eventually manifest themselves in physiological conditions such as high blood pressure, ulcers, headaches, and other health problems (Borg, 1990; Benbow \& Jolley, 2002; Anshel, Sutarso \& Jubenville, 2009). The conditions may also create, among others, psychological conditions of nervous tension and feelings of depression which affect an individual's well being (Sakharov \& Farber, 1983; McCormick \& Ilgen, 1985; Stumpfer \& Banks, 1996, Child, 2007). According to Brehm and Kassin (1996) and Hirsch (2001) occupational stress is a 
condition wherein job-related factors for example, work load, time pressures, and degree of control, interact with the worker's personal resources (i.e. professional skills, expectations, coping skills, dispositions) to change (disrupt/enhance) the worker's physiological or psychological condition, so that the person is forced to deviate from normal functioning.

Stress has been identified as major factor in ill-health, particularly psychological health. Work place surveys (Cooper \& Cartwright, 1994; Nhundu, 1999; Worral \& Cooper, 2001; Zindi, 2002) consistently report that employees consider that stress at work is a significant factor, which affects their health and well-being. There are two types of stress; eustress, which is good stress and distress, which is bad stress (Brehm, Kassin \& Fein, 2002; Anshel, Sutarso \& Jubenville, 2009). If a person perceives something as a danger, then the person will feel at harm. The perceived stress is a stressor, which then makes the individual feel stressed activating the changes in physiological responses (Benbow \& Jolley, 2002; Child, 2007).

Studies conducted in South Africa show that stress is a menace to various groups of people in a diversity of professions including health professionals (Strumpfer \& Bands, 1996; Eagle, 2002), prisoners (Vogelman, Lewis \& Segal, 1994; Strumpfer \& Bands, 1996), sports (Anshel \& Kaissidis, 1997), teachers (Nhundu, 1999; Zindi, 2002), police (Gulle, Tredoux \& Foster, 1998), clergymen (Strumpfer \& Bands, 1996), tertiary students (Hoffmann, 2002) and competitive athletes (Anshel, Sutarso \& Jubenville, 2009; Puente-Diaz \& Anshel, 2005) including women undergoing first trimester abortion (Faure \& Loxton, 2003 Kaur, 2011). Nhundu (1999) carried out a study on occupational stress among teachers and head teachers in Zimbabwe. Specifically, the study investigated the sources, incidence, and severity of stressful work situations and examined the influence of selected biographical characteristics on the respondents' perception. The findings showed that teachers rated their work more stressful than head teachers. Teachers also experienced more stress concerning working conditions, where the most stressful factor, irrespective of personal characteristics, was low salaries. Earlier study in Swaziland by Magagula (1994) among secondary/high school teachers in the Manzini region revealed results similar to that of Nhundu (1999).

\subsection{Teacher stress}

Teacher stress has been a subject of research for many decades. For example, about three decades back, Pettegrew and Wolf (1982) researched teacher stress and listed the following among others as causes of teacher stress: role related stress, task-based stress and environmental stress and indicated that dealing with teacher stress had already become a pertinent issue even then. They stated that "stress management seminars and the like all underscore a nationwide interest in teacher stress" (Pettegrew \& Wolf, 1982: 373). Montgomery and Rupp (2005), while researching the diverse causes and effects of teacher stress associate it, among others, with burn out and emotional response. Research conducted in several countries show that a large number of teachers report relatively high levels of occupational stress (see for example Borg 1990; Brehm, Kassin \& Fein, 2002). Studies, which have compared classroom teachers with other white-collar professional groups, have also revealed that teachers report high levels of work-related stress (Ngidi \& Sibaya, 2002; Rapmund \& Moore, 2000). Chan, Chen and Chong (2010) investigated teachers' stress in primary and secondary schools in Hong Kong. Teachers reported increased stress levels and attributed teacher stress to heavy workload, time pressure, education reforms, external school review, pursuing further education and managing students' behaviour and learning. Kaur (2011) did a comparative study of occupational stress among teachers of private and public schools in relation to their age, gender and teaching experience.

Child (2007: 264) observes that the changes in education system causes stress which affects teachers' motivation, and emphasizes "the introduction of so many innovations into school life, more detailed and time-consuming methods of assessment, more administration and committee meetings within the school have all conspired to increase tension in teaching". van Dick and Wagner (2001) sampled a total of 356 German teachers to test the theoretical model of teacher stress on a large sample using complex structural equation modeling. The results of the study revealed that the predictors of the stress model hold true: work load and mobbing lead to stress reactions, whereas principal support, beliefs of selfefficacy, and use of appropriate coping strategies reduces the perception of work load and mobbing. Again, in a recent study Jepson and Forrest (2006) studied 95 teachers from schools in the UK. A snowball sampling technique was used. There were 71 female teachers (68\%) and 24 male teachers (32\%). Teachers were recruited from both primary (68\%) and secondary (32\%). The aim of the study was to identity the role of individual contributory factors in teacher stress. The results revealed the strongest predictor of work-related stress, with a strong negative relationship as occupational commitment, indicating that as occupational commitment increases, perceived stress decreases. It also showed that significantly higher levels of 'perceived' were reported from primary school teachers than secondary school teachers. This study has therefore demonstrated that individual contributory factors are significant to the prediction and understanding of occupational stress experienced within the teaching profession. 
In their on teacher stress Santavirta, Solovieva \& Theorell (2007) investigated how different formulation or approaches of a high-strain job were related to teachers' burnout measured in terms of emotional exhaustion, vitality and emotional well-being. Another aim of the study was to empirically test the interaction between high demand and low decision authority, and to estimate the joint effect of these two risk factors on self-reported emotional exhaustion. The 1028 sample was drawn from the register of the Trade Union of Finland. The study produced several significant findings. Firstly, all three definitions of job strain were significantly associated with emotional exhaustion, vitality and emotional well-being independently of the effect of the confounders. Secondly, the results showed that the main effect of high demand exceeded the main effect of low decision authority in relation to emotional exhaustion, which means that the demand factor had a higher independent effect than decision authority in the burnout process. Furthermore, the study showed that the two factors acted synergistically to increase the risk of burnout among teachers.

To determine the relationship between black teachers' personalities and their stress levels on work-related factors Ngidi and Sibaya (2002) studied 444 African teachers, 258 of whom were female and 186 were male. The sample came from 24 randomly selected schools in the KwaZulu-Natal province. The results indicated significant regression of personality on the predictor variables such as time pressures, administrative problems and pupil's misbehavior. A significant positive relationship was found between neuroticism and time pressures, administrative problems and pupil misbehavior. The results also indicate significant three-way interaction effects for work-related stress factors such as time pressure and pupil misbehavior. Against this background, the present study focused on the 'causes of work-related stress among high school teachers in the Hhohho region of Swaziland'.

\subsection{Statement of the problem}

Minimal research has however been conducted into occupational stress amongst high school teachers in Swaziland, despite the demonstrated stressful nature of their work. Quite a number of teachers are not effective as they should in their teaching. Factors such as educational reforms, changing policies in education, inadequate teacher preparations on changes, high enrolment in schools and economic depression appear to contribute to poor lesson delivery. However, to the researchers' knowledge no study has been conducted in Swaziland to investigate work-related stress among high school teachers of the Hhohho region of Swaziland. It was therefore necessary to investigate work-related stress among teachers in the region.

\subsection{Purpose of the study}

The purpose of this study was to determine the level of work-related stress among high school teachers in the Hhohho region of Swaziland; ascertain aspects of teachers' job which are a main source of work-related stress among high school teachers in the Hhohho region of Swaziland; and determine if there is a significant relationship between the level of workrelated stress of high school teachers and their demographic variables.

\subsection{Research questions}

In order to meet the purposes of the study, the following research questions were used to guide the study:

1. What is the level of work-related stress among high school teachers in the Hhohho region of Swaziland?

2. Which aspects of teachers' jobs are the main sources of work-related stress among high school teachers in the Hhohho region of Swaziland?

3. What is the relationship between the level of work-related stress of high school teachers and their demographic variables?

\subsection{Significance of the study}

The study has many significant dimensions to it. It would provide empirical data and information on both the presence and sources of work-related stress among high school teachers. Specifically this study is significant in that it would provide empirical data for the Ministry of Education, School Administrators and Curriculum experts, on the existence of stress on teachers that arises as a result of their work. Such information would aid and enhance adjustments in both policies and practices in education, and teacher welfare. Generally the study would be of immense benefit to teachers, tutors and lecturers, social workers, guidance and career counsellors, and all categories of researchers both professionals and non-professionals who are interested in understanding work-related stress. 


\section{Theoretical Framework: Person-Environment Fit Theory}

There are diverse models of work-related stress that have stimulated the construction of a variety of stress measures in order to clarify and interpret research findings on work-related stress. For example, psychological theories (Lazarus, 1966, cited in Quinlan, 1988; Quinlan \& Bohle, 1991; Gulle, Tredoux \& Foster, 1998; Eagle, 2002), the sociological theories (James, 1989; William \& Thorpe, 1992; Berger, 1993), the systemic theories (McGrath, 1976; Karasek, 1979; Furnham \& Schaeffer, 1984; Karasek \& Theorell, 1990; Bacharach, 1991; Edwards, 1992), the demand-control theories (Cooper, 1983; Watson, Pennebaker \& Folger, 1986; Murphy, 1988; Frone \& McFarlin, 1989), the communication theory (Hart \& Wearing, 1995; Hoffman, 1981), the cybernetics theories (Levi, 1990; Decker \& Borgen, 1993), the stress work model (Marshall \& Cooper, 1979; Borg \& Riding, 1993), the state-trait process (STP) model (Spielberg \& Reheiser, 1994) and the Person-Environment Fit model-P-E Fit model (Lewin, 1951 in Lee \& Antonakis, 2007; Edwards, 1991; Shipp \& Jansen, 2008). The current study is grounded on the P-E Fit model.

\subsection{The P-E Fit model}

The P-E Fit model is widely accepted as a major conceptual framework for research on work-related stress because it is able to give adequate attention to both the ever-changing phenomenon of personality and the work environment (Wasala, 2001; Faure \& Loxton, 2003; Puente-Diaz \& Anshel, 2005). The P-E Fit is not a static model but a very dynamic one (Spokane, Meir \& Catalano, 2000; Furnham, 2005). It therefore helps to illustrate how individuals choose environments that create a good fit and how resultant P-E fit or misfit affects individual affective and behavioral outcomes in their careers. According to Kristof-Brown, Bono and Lauver (2002); and Roberts and Robins (2004) the P-E Fit theory is one of the few conceptualizations of a person's relationship to the environment that encompasses such a broad range of relationships. Lastly, the focus of the P-E Fit model is not only on individual behaviors but also on group or organizational behavior. Therefore predictions in this model include group or organizational as well as individual outcomes.

The Person-Environment Fit theory according to Shipp and Jansen (2008) is based on interactional psychology widely accepted formula, $B=f(P-E)$, which states that behaviour is a function of the person and the environment. Research on the P-E fit orientation suggests that the congruence between individual characteristics and environmental characteristics predict attitudes and behaviour (Adkins, Ravlin \& Meglino, 1996; Cable \& Judge, 1997). Muchinsky and Monahan (1987) cited in (Sekiguchi, 2004) correctly observe, whether a good fit today will be a good fit tomorrow depends on the stability of the variables on which matches are made. Some characteristics may be more changeable. For example, personality and values are often used in conceptualizing P-E Fit. Although both personality and values are considered relatively stable, values are less stable than personality and susceptible to the variety of changes and the influences of new environments (Caplan, 1987; Ryan \& Kristof-Brown, 2003; Sekiguchi, 2004). Therefore, while fit in terms of personality similarity may be relatively stable, fit in terms of value congruence may change over time. For Schneider, Smith \& Golstein (2000) the P-E Fit theory considers not only that the person and environmental influences on individual's behaviour, but that the fit between the person and the environment influences behavior.

Essentially, the P-E Fit model posits that there are characteristics of organizations that have the potential to be congruent with characteristics of individuals, and that the individuals' attitudes and behaviours will be influenced by the degree of congruence or fit between individuals and organizations (Roberts \& Robin, 2004; Furnham, 2005; Ellis \& Tsui, 2007). Hence the general assumption underlying P-E Fit model is that positive attitudes and behaviours are a function of the compatibility of individuals to their environments (Hoffman \& Woehr, 2006; Lee \& Antonakis, 2007). The application of this theory helped in the explication of occupational stress among high school teacher in the Hhohho region of Swaziland.

\section{Methodology}

\subsection{Design of the study}

This study followed the descriptive-correlation research design. According to Neuman (2003) and Bell (2005) descriptive research studies are non-experimental in that they deal with the relationships between non manipulative variables in a natural rather than laboratory setting. These researchers used the design because of its capacity to describe data whether in words, pictures, charts or tables, and whether the data analysis shows statistical relationship or is merely descriptive. 


\subsection{Area of study and target population}

The area of study was the Hhohho region, which is part of the Swaziland Highveld. The target population of this study was all qualified teachers teaching in high schools in the Hhohho region of Swaziland excluding principals and deputy principals. School administrators (principals and deputy principals) were excluded from this because they have different roles and sources of work-related stress that are unique to their positions. The Hhohho region has a total of 41 high schools. The total number of high school teachers in the region excluding school administrators is 1217 (Swaziland Government, 2007).

\subsection{Sampling procedures}

Simple random sampling procedure (Welman, Kruger \& Mitchell, 2007) was employed to select the schools and the teachers who participated in this study. Out of the 41 schools each one had an average of $(1217 / 41=30) 30$ teachers. To determine the sample size for the study, a sample of high school teachers drawn from using Krejcie \& Morgan (1970) formula for determining sample size. The sample size was 291 high school teachers that participated in the study coming from $(291 / 30=10) 10$ randomly selected schools. The sample of the study was 291 teachers taken from 10 randomly selected high schools in the Hhohho region of Swaziland. Of these 219 teachers, 131(45\%) were males and 160 55\%) were females.

\subsection{Pilot study}

Pilot testing was conducted in the first week of March, 2010 using a sample of thirty (30) high school teachers in the Manzini region. The purpose of the pilot study was to: develop and test adequacy of the research instrument; assess the proposed data analysis techniques to uncover potential problems; discard all unnecessary, difficult or ambiguous question items and re-word any question/items that were not answered as expected. Stratified systematic sampling procedures were used in order to include both males and females in the study. Fifteen male and fifteen females responded to the questionnaire. There was an indication that the items were clearly worded and the thirty participants did not experience any difficulties responding to the questionnaire items. An analysis of the items on the questionnaire for the 52 items showed correlations above 0.75 on each of the items. This was deemed to be high enough and the instrument was seen as yielding a satisfactory internal validity.

\subsection{Validity of Instrument}

According to Neuman (2003) the validity of a measurement procedure is the degree to which the measurement process measures the variables it intends to measure. The instrument for this study was given to experts in the Faculty of Education in one of the Universities in the Region to be reviewed for both face and content validity. Following the exercise, their recommendations were then incorporated into the final draft of the instrument.

\subsection{Reliability of the Instrument}

Reliability according to Cohen, Manion \& Morrison (2005) refers to measuring an instrument's ability to yield consistent numerical results each time it is applied. It does not fluctuate unless there are variations in the variables being measured (De Vos et al, 2005). To ensure instrument reliability, the researcher used Cronbach's alpha co-efficient. The reliability of the instrument was obtained at a Cronbach's alpha coefficient of .85. The instrument was deemed reliable since the obtained alpha coefficient (.85) was above the acceptable .70 .

\section{Method of Data Collection}

\subsection{Instrument}

Data for this study was collected by means of a questionnaire. A modified version of the questionnaire items developed by the Chartered Society of Physiotherapy (CSP, 2009) was adapted by the researchers for the present research situation and environment. The questionnaire was divided into three sections. The first section of the questionnaire on stress consisted of a 5 - point Likert scale where teachers indicated their level of work-related stress where 1=not 
stressful, 2=mildly stressful, 3=moderately stressful, 4=very stressful, 5=extremely stressful. The second section of the questionnaire consisted of a list of 46 stressors categorized according into 4 aspects (Work environment, Nature of the work, Work relationships, and Contractual problems) of the teachers' job. Respondents were requested to indicate the degree to which that particular statement was a source of stress at work on a-5 point Likert-type rating scale calibrated as follows: 1=not stressful, 2=mildly stressful, 3=moderately stressful, 4=very stressful, 5=extremely stressful. The Likerttype format is preferred because, according to de Vos, Strydom, Fouche \& Delport (2005), this format yields equalinterval data, a fact that allows for the use of more powerful statistics to be used to test variables. The last section sought demographic data (Gender, Age, Marital status, Qualifications) for the respondents.

\subsection{Ethical measures and questionnaire administration}

The researchers wrote letters to the respective principals for the selected schools for permission to carry out the study. This preliminary request was also to help explain the rationale of the investigation and the way it was organized. After the principals' approval of the request, the lead researcher personally administered the questionnaire to the sample of 291 high school teachers 10 randomly selected schools in the Hhohho region of Swaziland. Respondents were informed of the anonymous and confidential nature of their participation. The participants gave their informed consent. At no stage, even after the investigation was completed would their persons or responses be revealed to their principals or their employer nor to the Teaching Service Commission. The researchers waited to collect the questionnaire from the respondents after they had completed them. By so doing the researchers ensured that a favourable rate of return was achieved. Out of the 291 questionnaires, 239 usable questionnaires were received from the respondents, thus, making a response rate of $82 \%$. This gave a very fovourable rate of return compared with similar studies by and Nhundu (1999) and Ngidi \& Sibaya (2002).

\subsection{Methods of data analysis}

The Statistical Package for the Social Sciences (SPSS) version 10.0 was used to compute the information regarding the level of work-related stress, work-related stressors, and the relationship between work-related stress and demographic variables (gender, age, marital status, qualification) of high school teachers. The data were analyzed using the following procedures: the mean and standard deviation was obtained to determine the level of work-related stress for the sample; means and standard deviations were obtained for all the aspects of teachers' jobs to determine those job aspects which were major sources of work-related stress for teachers; Pearson Product Moment Correlation Coefficient was used to examine the relationships between the mean score of work-related stress and demographic variables.

\section{Results}

Table 1: Demographic Data of the Sample $(N=239)$

\begin{tabular}{lcc}
\hline Variable & Frequency & Percentage \\
\hline Female & Gender & \\
Male & 117 & 49.0 \\
& 121 & 50.6 \\
& & \\
$20-29$ & Age & \\
$30-39$ & 49 & 20.5 \\
$40-49$ & 102 & 42.7 \\
$50-60$ & 63 & 26.4 \\
& 25 & 10.5 \\
& & \\
Single & Marital Status & \\
Married & 68 & 28.5 \\
Divorced & 119 & 49.8 \\
Widowed & 25 & 10.5 \\
Separated & 10 & 4.2 \\
& 17 & 7.1 \\
& & \\
STD & Qualification & 15.1 \\
BA + PGCE & 36 & 24.7 \\
BSC+ PGCE & 59 & 26.4 \\
BA BSC + CCECDE & 63 & 7.9 \\
B.ED & 43 & 18.0 \\
Other & 19 & 7.9 \\
& &
\end{tabular}


Table 1 reports the demographic characteristics of the sample $(N=239)$. There were $117(49.0 \%)$ females and 121 (50.6\%) males in the sample. The ages of the participants varied from the $20-29$ years old age range to the $50-60$ years old age range. A total of 102 (42.7\%) participants were in the $30-39$ years old age range and were the majority. They were followed by participants in the $40-49$ years old age range being 63 (26.4\%). There were 49 (20.5\%) participants in the $20-29$ years old and $25(10.5 \%)$ in the $50-60$ years old range.

The majority of the sample, being $199(49.8 \%)$, reported being married. A total of $68(20.5 \%)$ were single. There were 25 (10.5\%) divorced, 10 (4.2\%) and 17 (7.1) who were separated. BSC + PGCE was the most commonly reported qualification with 63 (26.4\%) participants. There were 59 (24.7\%) BA + PGCE holders, 43 (18.0\%) B.ED holders and 19 (7.9\%) BA/BSC + CCE/CDE holders. A total of $36(15.1 \%)$ of the participants had the STD qualification while other qualifications amounted to $19(7.9 \%)$ participants.

The results of this study provided information about the sample's level of work-related stress, job aspects that are prevalent stressors and the relationship between the level of work-related stress and demographic characteristics of the sample.

\subsection{Research question 1}

What is the level of work-related stress among high school teachers in the Hhohho region of Swaziland?

Table 2: Mean and standard deviation for the level of work-related stress among high school teachers $(\mathrm{N}=239)$

\begin{tabular}{llll} 
& $\mathrm{N}$ & $\mathrm{M}$ & $\mathrm{SD}$ \\
\hline Level of work-related stress & 239 & 3.1088 & 1.0555 \\
\hline
\end{tabular}

The respondents rated their level of work-related stress on a 5 point Likert scale where: $1=$ Not stressful, $2=$ Mildly stressful, $3=$ Moderately stressful, $4=$ Very stressful, $5=$ Extremely stressful. The mean level of work-related stress was 3.1088 with a standard deviation of 1.0555. This means that high school teachers in the Hhohho region of Swaziland are moderately stressed by their jobs.

\subsection{Research question 2}

Which aspects of teachers' jobs are the main sources of work-related stress among high school headteachers?

Table 3: Means and standard deviations of aspects of teachers' jobs causing work-related stress among high school teachers $(\mathrm{N}=239)$

\begin{tabular}{lll}
\hline Job aspect & Mean & SD \\
\hline Contractual problems & 3.2490 & 1.3540 \\
Nature of the work & 3.1569 & 1.3643 \\
Work environment & 2.9429 & 1.3563 \\
Work relationships & 2.6057 & 1.2680 \\
\hline
\end{tabular}

Note: Ranked in descending order from most prevalent to least prevalent

In table 3 the aspects of teachers' jobs were ranked in descending order according to means. This was to indicate which job aspects were the main sources of work-related stress for high school teachers. The teachers reported to be stressed by all four (4) job aspects. They reported to be moderately stressed by contractual problems (3.2490) and the nature of their jobs (3.1569). They were mildly stressed by their work environments (2.9429) and relationships in the work place (2.6057). 


\subsection{Research question 3}

What is the relationship between the level of work-related stress of high school teachers and their demographic variables?

Table 4: Correlations between the work-related stress level and demographic variables ( $N=239$

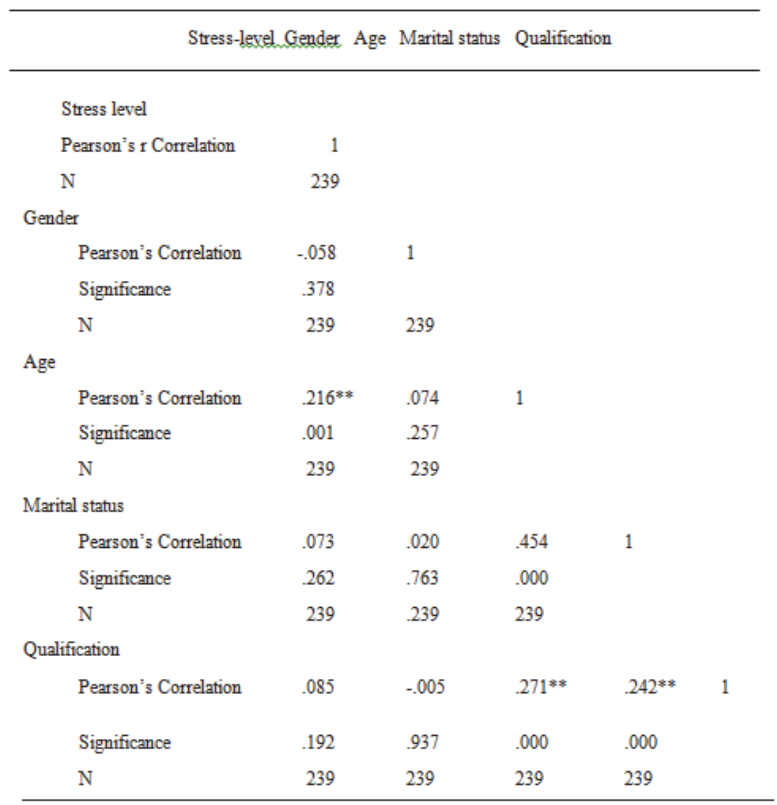

** Correlation is significant at the 0.01 level (2-tailed)

Table 4 shows the relationship between the level of work-related stress of high school teachers in the Hhohho region of Swaziland and their demographic characteristics (gender, age, marital status, qualifications). Results showed that:

- $\quad$ there was no significant relationship between work-related stress and gender among high school teachers $(r=$ $-.058, p=.374)$. This was a weak relationship as well as a negative one.

- $\quad$ there was a significant relationship between work-related stress and age among high school teachers $(r=216$, $p=.001)$. This was a moderate and positive relationship indicating that stress level increased with increasing age of respondents.

- there was no significant relationship between work-related stress and marital status among high school teachers $(r=073, p=.262)$. This was a very weak relationship.

- that there was no significant relationship between work-related stress and qualification among high school teachers $(r=085, p=.192)$. This was also a weak relationship.

These were relationships between the demographic characteristics of the sample. There was a moderate relationship between marital status and age $(r=454, p=.000)$ which was also statistically significant. Qualifications correlated significantly with both age $(r=.271, p=.000)$ and marital status $(r=.242, p=.000)$. These, however, were weak correlations.

\section{Discussion}

No work environment can ever be completely immune to stress. There are, however, indicators evident in the present study that some job aspects are more stressful than others. The level and impact of stressful work-related factors on the teaching profession has been revealed in this study. Teachers experience stress in different ways and level of stress is associated with the aspect of the job namely contractual problems and nature of work. Common to all these (stressors), is the economic change experienced in Swaziland, which is considered to be the underlying cause of stress. 
The findings indicated that the first and major source of work-related stress was a result of contractual problems. Under contractual problems there is lack of power and influence, threat of job loss, performance related incentives, poor pay, lack of accommodation, badly planned changes, temporal contracts and shortage of teachers. Threat of job loss and temporal contracts are perceived in this study to have a strong linkage in that teachers who work under contract are normally given contracts ranging from three months (one-term) to six months (two-terms). These teachers work under stress in that there is no guarantee that their contracts would be renewed once they expire. The possibility of losing a job any time is indeed a stressful event for these teachers. Moreover, contract teachers work without pay for many months; this poses a serious financial challenge to which is a great source of stress. Performance related incentives poor pay and lack of accommodation in schools are all a result of monetary problems. The Swaziland economy has failed to perform over the years, due to the high incidence of HIVIAIDS, resulting in high numbers of Orphaned and Vulnerable Children leading to high levels of poverty. All these factors have a strong bearing on poor remuneration and performance incentives for teachers. Accommodation appears to be a perennial problem for most school. There is either no accommodation or very little of it, forcing teachers to share. These are major source of stress for teachers.

The finding that changes in education is a major factor among sources of stress for high school teachers in the Hhohho region accords with those reported in South Africa and Zimbabwe (Ngidi \& Sibaya, 2002 and Zindi, 2002). These researchers maintain that it is not that teachers object to the changes themselves, but to the manner in which they are implemented. The badly planned education reforms in Swaziland necessitate drastic changes from the International General Certificate of Education (IGCE) to the International General Certificate Secondary of Education (IGCSE) and the present curriculum, the Swaziland General Certificate of Secondary Education (SGCSE). The problems facing teachers are due to the fact that the major changes have not adequately been accompanied by appropriate changes in facilities and training, in order to equip teachers to deal with these new demands. Consequently, teachers may feel threatened by the new demands, thus becoming stressed.

The findings also revealed the nature of the work as the second major source of work-related stress. Under this job aspect there is work overload, time pressure and deadlines, long working hours, taking work home, unrealistic objectives, making mistakes, boring or repetitive work and keeping students occupied. The findings of this study are consistent with those of other researchers (Borg \& Riding, 1993; Ngidi \& Sibaya, 2002 and Nhundu, 1999) in showing that work overload, keeping deadlines and taking work home were the greatest sources of stress among teachers. These findings also concur with those of (Anshel \& Kaissidis, 1997; Kokkinos, 2007; Magagula, 1994 and Pithers \& Soden, 1998) in reporting that teachers experience stress as a result work overload, keeping with time-lines, long working hours, doing school work at home and dealing with students.

Another finding concerns the interaction of gender, qualification, experience and marital status teachers experience in relation to poor pay and performance incentives. An observation is made that regardless of these demographic variables teachers experience more stress from poor pay and performance incentives. Undoubtedly, these working conditions reduce teachers' happiness in their work situation as well as their efficiency. The findings of this study appear to agree with those of (Cooper \& Cartwright, 1994 and Santavirta, Solovieva \& Theorell, 2007) where they reported that teachers experienced high levels of stress as a result of poor remuneration packages and fringe benefits in spite of the volume and challenging work that they do. Undoubtedly, these working conditions reduce teachers' happiness in their work situation as well as their efficiency.

This study provided information that is important to teaching administration and teachers' welfare. It was found that the teachers in this sample were moderately stressed with their work. They were stressed mainly by contractual problems and the nature of their work. The study also revealed that age was the only demographic characteristic that had a positive statistically significant relationship with work-related stress-level for the sample. The teachers' job could be improved using the results of this study. Teaching administrators will know that they need to do more to improve teachers' lives in the work place since they are moderately stressed. It would be an advantage to students, school administrators and parents to have less stressed teachers in schools. The major sources (Contractual problems and Nature of the work) of work-related stress for teachers have implications for the Teaching Services Commission, which is the teachers' employer and school principals who are teachers' supervisors in the work place.

\section{Summary of Findings}

The findings of the study showed that high school teachers in the Hhohho region of Swaziland are moderately stressed. The major source of stress for teachers was contractual problems which included the following stressors: lack of power and influence, threat of job loss, performance related objectives, poor pay, lack of accommodation, badly planned changes, temporal contracts and shortage of teachers. The findings also showed a weak relationship between work- 
related stress and demographic variables (gender, age, marital status, academic qualification).

\section{Conclusions}

On the basis of the data presented and analyzed in this study, the study showed that teachers are moderately stress by their work. The study revealed contractual problems as the major stressful aspect of their job and this component includes the following stressors: lack of power and influence, threat of job loss, performance related incentives, poor pay, lack of accommodation badly planned changes, temporal contracts and shortage of teachers. The least source of stress for teachers came from job aspect of work relationships and this included the following stressors: physical and sexual harassment, conflict between personal and school beliefs, unsympathetic boss, spousal attitude towards partner's work, relationship between work demands and the teacher's family, work demands on teacher's private life, collegial relationship, complaints/criticism from parents or public, feeling undervalued, lack of support from parents, law suits from parent and too much supervision.

\subsection{Implications of the findings to existing literature}

The results and findings of this study are consistent with what existing literature has revealed that the work of teachers is stressful. The nature of stressors identified by this study as stressful events have also been identified by other researchers elsewhere (Kokkinos, 2007 in Cyprus; Nhundu, 1999 in Zimbabwe; Ngidi \& Sibaya, 2002 in South Africa; Santavirta, Solovieva \& Theorell, 2007 in Finland).

\subsection{Recommendations for action}

Considering the findings of this study, it is strongly recommended that urgent measures are needed to alleviate the stressful situation of teachers before some of the more serious consequences set in. Assistance should be made available to teachers on stress management and prevention during teacher and head teacher preparation and thereafter. The preventative function of such a programme should include manipulating factors in the work environment so that there a good person-environment fit develops. In addition, stress management programmes for teachers should be different from those for head teachers because of dissimilarities in stress sources for the two sub-groups. With proper training, head teachers can work towards creating a supportive and enabling school environment that minimizes stress and foster supportive relationships for themselves and teachers.

\section{References}

Adkins, C. L., Ravlin, E. C., \& Meglino, B. M. (1996). Value Congruence between co-workers and its relationship to work outcomes. Group and Organization Management, 21(4): 439460.

Anshel, M. H., \& Kaissidis, A. N. (1997). Coping Style and Situational Appraisal as predictors of Coping Strategies Following Stressful Events in Sport as a Function of Gender and Skill level. British Journal of Psychology, 88(12): 263-276.

Anshel, M. H., Sutarso, T., \& Jubenville, C. (2009). Racial and Gender Differences of Sources of Acute Stress and Coping Style Among Competitive Athletes. The Journal of Social Psychology, 149(2): 159-177.

Antonious, A. S. G., \& Cooper, C. L. (2005). Research Companion to Organizational Health Psychology. Cheltenham: Edward Elgar.

Bacharsch, S. B. (1991). Work-Home Conflict among Nurses and Engineers: Mediating the Impact of role of Stress on burnout and Satisfaction at Work. Journal of Organizational Behaviour, 12(1): 39-53.

Bell, J. (2005). Doing your Research Project: A Guide to First-Time Researchers in Education, Health and Social Science. New York: Open University Press.

Benbow, S. M., \& Jolley, D. J. (2002). Burnout Stress amongst Old Age Psychiatrists, International Journal of Geriatric Psychiatry, 178(8): $710-714$.

Berger, Y. (1993). The Hoeclist dispute: A Paradigm Shift in Occupational Health and Safety. Melbourne: McMillan,

Borg, M. G. (1990). Occupational Stress in British Educational Settings: A Review. British Journal of Educational Psychology, 10: $103-126$.

Borg, M. G., \& Riding, R. L. (1993). Teacher Stress and Cognitive Style. British Journal of Educational Psychology, 63: 271-286.

Brehm, R. A., Kassim, S. M. \& Fein, S. (2002). Social Psychology. New York: Houghton Mifflin Company

Brehm, S. S., \& Kassim, S. M. (1996). Social Psychology. Houghton Mifflin Company, Boston: Houghton Mifflin Company

Cable, D. M., \& Judge, T. A. (1997). Interviewers' Perceptions of Person-Organization fit and Organizational Selection Decisions. Journal of Applied Psychology, 82 (4): 546-561.

Caplan, R. D. (1987). Person-Environment Fit Theory and Organisations: Commensurate Dimensions, Time Perspective and Mechanisms. Journal of Vocational Behaviour, 31: 248-267. 
Chan, A.H.S., Chen, K. \& Chong, E.Y.L. (2010) Work stress from primary and secondary schools in Hong Kong. Proceedings of the International Multiconference of Engineers and Computer Scientists. Vol III. March 17-19, Hong Kong.

Chartered Society of Physiotherapy (CSP) (2009). Health and safety information paper: Workplace stress. Retrieved from: http://www.csp.org.uk/sites/files/csp/ Accessed 17 March, 2014.

Child, D. (2007). Psychology and the Teacher. $8^{\text {th }}$ edition. New York: Continuum International Publishing Group.

Cohen, L., Manion, L., \& Morrison, K. (2005). Research Methods in Education. London. Routledge Falmer.

Communication Workers Union (2001, March). Stress Survey. London: Labour Research Department, Health Safety and Environment Committee.

Cooper, C. L. (1983). Identifying Stressors at work: Recent Research Developments. Journal of Psychosomatic Research, 27(5): 369-376.

Cooper, C. L., \& Cartwright, S. (1994). Health Mind; Healthy Organization-A Proactive Approach to Occupational Stress. Human Relations, 47(4): 455-578.

Decker, P. J., \& Borgen, F. H. (1993). Dimensions of work Appraisal: Stress, Strain, Coping, Job Satisfaction and Negative Affectivity. Journal of Counseling Psychology, 40(4): 470-478.

De Vos, A. S., Strydom, H., Fouche, C. B., \& Delport, C. S. L. (2005). Research at Grassroots: for the Social Sciences and Human Service Professions. Pretoria: van Schaik Publishers.

Eagle, G. T., (2002). Special Feature: Critical Contexts of Pathology Posttraumatic Stress Disorder (PTSD): The Malleable Diagnosis? South African Journal of Psychology, 32(2): 37-42.

Edwards, J. R. (1991). Person-Job fit: A conceptual integration, literature review, and methodological critique. International Review of Industrial and Organizational Psychology, 6: 283-357.

Edwards, J. R. (1992) A Cybernetic Theory of Stress, Coping, and well-being in Organisations. Academy of Management Review, 17(2): 238-274.

ETUCE (2011) European Trade Union Committee for Education. Teachers' work-related stress: assessing, comparing and evaluating the impact of psychosocial hazards on teachers at their workplace. Brussels: ETUCE.

Ellis, A., \& Tsui, A. S. (2007). Survival of the fittest or the least fit? When psychology meets Ecology in organizational Demography: Perspectives on Organizational Fit. New York: Lawrence Erlbaum Associates.

Faure, S., \& Loxton, H. (2003). Anxiety, Depression and Self-efficacy Levels of Women Undergoing First Trimester Abortion. South African Journal of Psychology, 33(1): 28-90.

Frone, M. R., \& McFarlin, D. B. C. (1989). Chronic Occupational Stressors, Self-Focused attention, and well-being: Testing a Cybernetic Model of Stress. Journal of Applied Psychology, 74(6): 876-883.

Furnham, A. (2005). The Psychology of Behaviour at Work: The Individual in the Organization. New York: Psychology Press.

Furnham, A., \& Schaeffer, R. (1984). Person-Environment Fit, Job Satisfaction and Mental Health. Journal of Occupational Psychology, 57: 295-307.

Gulle, G., Tredoux, C., \& Foster, D. (1998). Inherent and Organizational Stress in the SAPS: An Empirical Survey in the Western Cape. South African Journal of Psychology, 28(3): 129-134.

Hart, P. M., \& Wearing, A. J. (1995). Occupational Stress and well-being: A Systematic Approach to Research, Policy and Practice. Victoria: Australian Psychological Society.

Hirsch, G. (2001). Helping College Students Succeed: A Model for Effective Intervention. Philadelphia: Routledge

Hoffman, L. (1981). Foundations of Family Therapy. New York: Basic Books.

Hoffman, B. J., \& Woehr, D. J. (2006). A Quantitative Review of the Relationship between Person-Organization Fit and Behavioural Outcomes. Journal of Vocational Behavior, 68: 389-399.

James, C. R. (1989). Social Sequel of Occupational Injury and Illness. Unpublished Doctoral dissertation, Griffith University, Australia.

Jepson, E., \& Forrest, s. (2006). Individual contributing factors in teacher Stress: The Role of Achievement Striving and Occupational commitment. British Journal of Educational Psychology, 76: 183-197.

Karasek, R. A. (1979). Job Demands, Job Decision Latitude, and Mental Strain: Implications for Job Redesign. Administrative Science Quarterly, 24: 285-308.

Karasek, R. A., \& Theorell, T. (1990). Healthy Work: Stress, Productivity and the Reconstruction of Working Life. New York: Basic Books.

Kaur, S. (2011). Comparative study of occupational stress among teachers of private and Govt. schools in relation to their age, gender and teaching experience. International Journal of Educational Planning \& Administration, 1 (2): 151-160.

Kokkinos, C. M. (2007). Job Stressors, Personality and Burnout in Primary School Teachers. British Journal of Educational Psychology, 77: 229-243.

Kompier, M. and Cooper, C. (1999). (ed.) Preventing stress, improving productivity: European case studies in the workplace. New York: Rotledge.

Kristof-Brown, A. L., Bono, J. E., \& Lauver, K. J. (1999). Learning to fit in: How Socialization Affects Perceived and Actual PersonEnvironment fit. Paper presented at the 14th annual conference of the Society for Industrial and Organizational Psychology, Atlanta, GA.

Lee, \& Antonakis, J. (2007). Moderating Effect of National Culture on Person-Environment Fit: A Comparative Study in Asian and European Countries. Working Paper 0602. Institute of Research in Management.

Levi, L. (1990). Occupational Stress: Spice of life or kiss of death? American Psychologist, 45(10): 1142-1145.

Loate, I.M. \& Marais, J.L. (1996). Stress and stress management strategies among Batswana women lecturers. South African Journal of Higher Education, 10 (2): 92-100. 
Magagula, R. F. (1994). Causes of Stress among Secondary/High Teachers in the Manzini Region of Swaziland. Unpublished B.Ed. Thesis, Kwaluseni: University of Swaziland.

Marshall, J., \& Cooper, C. (1979). Work Experiences of Middle and Senior Managers: The Pressure and Satisfaction. International Management Review, 19: 81-96.

McCormick, E. J., \& Ilgen, D. (1985). Industrial and Organizational Psychology. London: Allen \& Unwin,

McGrath, J. E. (1976). Stress and Behaviour in Organisations: Handbook of Industrial and Organization Psychology. Chicago: Rand McNally.

Montgomery, C. \& Rupp, A.A. (2005). A meta-analysis for exploring the diverse causes and effects of stress in teachers. Canadian Journal of Education, 28 (3): 458-486.

Murphy, L. R. (1988). Workplace Interventions for Stress Reduction and Prevention: Causes, Coping and Consequences of Stress at Work. London: Wiley.

Neuman, W. L. (2003). Social Research Methods: Qualitative and Quantitative Approaches. Madrid: A and B.

Ngidi, D. P., \& Sibaya, P. T. (2002). Black Teachers' Personality Dimensions and Work-Related Stress Factors. South African Journal of Psychology, 32(3): 7-15.

Nhundu, T. J. (1999) Stress in the Teaching Profession: A Comparative Study of the Sources, Incidence and Severity of Occupational Stress of Teachers and Head Teachers in Zimbabwe. Zimbabwe Journal of Educational Research, 7(2): 1-33.

Pettergrew, L.S. \& Wolf, G.E. (1982). Validating measures of teacher stress. American Educational Research Journal, 19 (3): $373-396$.

Pithers, R. T., \& Soden, R. (1998). Scottish and Australian Teacher Stress and Strain: A Comparative Study. British Journal of Educational Psychology, 68: 269-279.

Puente-Diaz, R., \& Anshel, M. H. (2005). Sources of Acute Stress, Cognitive Appraisal, and Coping Strategies among Highly Skilled Mexican and U.S. Competitive Tennis Players. The Journal of Social Psychology, 145(10): 429-444.

Quinlan, M., \& Bohle, P. (1991). Managing Occupational Health and Safety in Australia. Melbourne: McMillan.

Rapmund, V., \& Moore, C. (2000). Women's Stories of Depression: A Constructivist Approach. South African Journal of Psychology, 30(2): 20-29.

Roberts, B. W., \& Robins, R. W. (2004). Persona-Environment Fit and it's Implications for Personality Development: A Longitudinal Study. Journal of Personality, 72(1): 89-110.

Ryan, A. M., \& Kristof-Brown, A. L. (2003). Focusing on Personality in Person-Organization Fit Research: Unaddressed Issues. Personality and Work, Journal of Vocational Behavior, 58: 188-204.

Sakharov, M., \& Farber, B. A. (1983). A Critical Study of Burnout Teachers. New York: Pergamon Press,

Santavirta, N., Solovieva, S., \& Theorell, T. (2007). The Association between Job Strain and Emotional Exhaustion in a Cohort of 1028 Finnish Teachers. British Journal of Educational psychology, 77: 213-228.

Sekiguchi, T. (2004). Person-Organization fit and Person-Job fit in employee Selection: A review of literature. Osaka Keidai Ronshu, 54: 179-196.

Shipp, A. J., \& Jansen, K. J. (2008). The temporality of person-environment fir Perceptions: The role of retrospection and anticipation. Paper presented at the 64th annual meeting of the Academy of Management, Honolulu, $\mathrm{HI}$.

Sliskovic, A. \& Sersic, D.M. (2011). Work stress among university teachers: gender and position differences. Arh Hig Rada Toksikol, (62): 299-307.

Speilberger, C, D., \& Reheiser, E. C. (1994). The Job Stress Survey: Measuring Gender Differences in Occupational Stress. Journal of Social Behaviour and Personality, 9(2): 199-218.

Spokane, A. R., Meir, E., \& Catalano, M. (2000). Person-Environment Congruence and Holland's Theory: A review and reconsideration. Journal of Vocational Behavior, 57: 137-187.

Stumpfer, D. J. W., \& Bands, J. (1996). Stress Among Clergy: An Exploratory Study on South African Anglican Priests. South African Journal of Psychology, 26(2): 67-74.

Swaziland Business Year Book (2007). A Commercial Guide. Mbabane.

Swaziland Government (2007). Education Statistics. Mbabane: Central Statistics Office.

Tam, T. S. K., \& Mongy, L. P. K. (2005). Job Stress, Perceived Inequity and Burnout among School Social workers in Hong Kong. International Social work, 48(4): 467-483.

van Dick, R., \& Wagner, U. (2001). Stress and Strain in Teaching: A Structural Equation Approach. British Journal of Educational Psychology, 71: 243-259.

van Zyl, E. \& van Zyl, E. (2012). The management of work stress with the aid of certain personality variables in middle level management personnel. J. Soc. Sc, 30 (3): 225-234.

Vogelman, L., Lewis, S. and Segal, L. (1994). Life after Death Row: Post Traumatic Stress and the Story of Philip Takedi. South African Journal of Psychology, 24(2): 91-99.

Wasala, D. F. (2001). Organizational Stressors and Work-Related Stress. Unpublished Master's thesis, University of South Florida, USA.

Watson, D., Pennebaker, J. W., \& Folger, R. C. (1986). Beyond Negative Affectivity: Measuring Stress and Satisfaction in the workplace. Journal of Organizational Behaviour Management, 8 (2): 141-157.

Welman, C., Kruger, \& Mitchell, B. (2007). Research Methodology. Cape Town: Oxford University Press.

William, C., \& Thorpe, B. (1992). Beyond Industrial Sociology: The work of women. Sydney: Allen and Unwin.

Worral, L., \& Cooper, C. L. (2001). The Quality of Working Life Survey. London: Institute of Management.

Zindi, F. (2002). An Investigation into Teachers' Stress and Physical well-being. Zimbabwe Journal of Educational Research, 14(1): 57-70. 